\title{
Mi caminar con Ignacio Ellacuría
}

\section{Jon Sobrino, s.j. Universidad Centroamericana "José Simeón Cañas"}

\section{Ignacio Ellacuría Beascoetxea, un ser humano}

Mi buen amigo Héctor Samour me pidió participar en el Coloquio internacional conmemorativo de los 30 años del asesinato de lgnacio Ellacuría. Mi primera respuesta fue que ya he hablado y escrito suficientemente sobre Ellacuría y que no tengo nada nuevo que decir, y menos en un Encuentro organizado por dos instituciones que se dedican a tareas específicas. Una, a la filosofía. Otra, al análisis de la realidad política y social. Mi amigo Héctor insistió y acepté. Después, al recibir la invitación oficial, caí en la cuenta que el encuentro pretende más en concreto poner al día y evaluar la vigencia del pensamiento de Ellacuría. Me parece importante y siempre oportuno, y les felicito a ustedes por hacerlo.

Hablando con sinceridad no me creo suficientemente capacitado para llevar a cabo ninguna de las dos cosas. En lo que voy a decir no pretendo, pues, poner al día el pensamiento de Ellacuría ni evaluar su vigencia. Me voy a concentrar en el ser humano Ignacio Ellacuría
Beascoetxea, tal como lo conocí, con quien conviví, trabajé, gocé y padecí 15 años, en comunidad con otros jesuitas, cinco de ellos asesinados con él. Y con Ellacuría, aunque cada uno lo hizo por su cuenta, con él tuve dudas sobre Dios y con él recé a Dios.

El Ellacuría pensante y científico ciertamente me impactó. De él aprendí muchas cosas, y a través de él -como por ósmosis- también creo que aprendí algunas cosas de Zubiri. Y pienso que él también aprovechó algo de lo que yo pensaba, lo que voy a mencionar para enfatizar que nos relacionábamos sobre todo como seres humanos. De la teología que yo traía de Alemania, le impactó en concreto el reino de Dios, y me vino a preguntar sobre ello. En un encuentro de teólogos en Córdoba en 1989, dijo que "lo mismo que Jesús vino a anunciar y realizar, esto es, el reino de Dios, es lo que debe constituirse en el objeto unificador de toda teología cristiana, así como de la moral y de la pastoral cristiana: la mayor realización posible 
del reino de Dios en la historia es lo que deben perseguí los verdaderos seguidores de Jesús".

Y también reaccionó con sorpresa y aprobación ante mi audacia -digamos- de añadir a su estupenda tríada de "hacerse cargo de la realidad", "encargarse de la realidad" y "cargar con la realidad", una cuarta cosa: "dejarse cargar por la realidad". Saqué el tema en la defensa de una tesis sobre Zubiri en la que él era el presidente del tribunal y yo un miembro, tal como él me pidió. Le pregunté al estudiante candidato qué decía Zubiri de la gracia. Ellacuría se volvió a verme con un cierto aire de sorpresa. Yo pensé que mi pregunta tenía sentido. $Y$ que lo que es gracia bien puede formularse en lenguaje de lo humano como un "dejarse cargar por la realidad".

Esto lo recuerdo para expresar mi convicción fundamental. Ellacuría ciertamente era superior en ciencia $y$ en conocimientos a este servidor, pero, ante todo, ambos nos movíamos en el ámbito de lo humano. Y lo que he recordado quizás ayuda a comprender que en ese ámbito nos podíamos relacionar.

En definitiva, eso es lo que más me impactó de Ellacuría. Su humanidad se expresaba en su pensar $e$ intelegir, e igualmente en su lucha por la justicia y los derechos humanos, y más específicamente en la defensa de los oprimidos en contra de sus opresores, no solo en la ayuda, que concreta 0 estructuralmente buscan exterminarlos. Así habla Puebla de la opción de Dios por los pobres: "Dios busca su defensa", "y los ama”. Así era el Ellacuría misericordioso.

Muchas veces me han pedido participar en encuentros sobre Ellacuría y, si mal no recuerdo, siempre he aceptado. Y por tener delante al Ellacuría ser humano, quizás siempre me he fijado en cosas que no suele ser lo habitual en esos encuentros -lo cual obviamente no quiere decir que mis reflexiones sean mejores ni más útiles que lo que exponen otros. Sí pienso que son necesarias, y ojalá sean útiles. Por ejemplo, en 1999 , en un libro que recogía artículos importantes sobre la persona de Ellacuría, me pidieron escribir el prólogo y me vino a la mente un tema que no era tratado en los artículos: la fe de Ellacuría. Al escribir el prólogo, lo completé, titulándolo: "Monseñor Romero y la fe de Ignacio Ellacuría”.

En 2010 escribí un artículo que titulé “El Ellacuría olvidado. Lo que no se puede dilapidar". Y mencioné tres cosas de Ellacuría que pienso que no rara vez se solían olvidar: 1. El pueblo crucificado es siempre "el" signo de los tiempos. 2. La salvación que viene de abajo. En especial "la civilización de la pobreza". 3. "Con Monseñor Romero Dios pasó por El Salvador". Mi intención no era en absoluto molestar a nadie al hablar de olvidos, aunque no 
sé si siempre lo conseguí. Recuerdo una vez que al analizar cómo se puede diagnosticar la enfermedad de la realidad, citando al mismo Ellacuría usé el término coproanálisis. Y después de la conferencia oí que alguien comentaba -sin maldad y con gracejo, pero con sorpresa-: "Total, nos hemos enterado de que Ellacuría habló de coproanálisis".
$Y$ antes de continuar quiero decir que del Ellacuría ser humano mucho me impactó el Ellacuría jesuita, discípulo de san Ignacio, seguidor de Jesús. El Ellacuría que vivió largos años a vueltas con Dios. Y en los últimos años -esa es mi convicciónel Ellacuría convertido por Monseñor Romero.

\section{Caminar humana y cristianamente}

Lo que he dicho hasta ahora son recuerdos personales de Ignacio Ellacuría quizás no muy mencionados en encuentros y congresos. Ahora quiero mencionar lo que en $\mathrm{mi}$ opinión es, o desearía que fuese, un "caminar humano y cristiano". En este contexto, no me suele venir a la mente el atinado y hondo caminar existencial y creador de Antonio Machado: $Y$ confieso que me encanta cómo canta el caminar Joan Manuel Serrat:

"Caminante, son tus huellas el camino, y nada más; Caminante, no hay camino, se hace camino al andar".

Más bien pienso en el caminar jesuánico de Pedro Casaldáliga
"Camino que uno es, que uno hace al andar.

Para que otros caminantes puedan el camino hallar.

Para que los atascados se puedan reanimar.

Para que los muertos no dejen de estar."

Don Pedro comparte con Machado que el caminante se enfrenta -él solo, sin un camino programadocon el caminar. Pero, a diferencia de Machado, insiste en lo que debe pretender el caminante:

Que otros caminantes puedan el camino hallar.

Que los atascados se puedan reanimar.

Que los muertos no dejen de estar.

\section{Con Ignacio Ellacuría}

Voy a decir tres cosas sobre el ser humano Ignacio Ellacuría que yo conocí, pienso que bastante bien. Con él conviví y trabajé cercana- 
mente alrededor de quince años. Tuve con él una buena amistad. Con cierta frecuencia hablamos de cosas de teología y alguna vez de filosofía, y también de cosas personales. Algunas veces me corrigió con sensatez y acierto, y a veces aprobaba lo que yo hacía, incluso con alguna alabanza. Yo le llamé la atención, muy pocas veces, y le agradecí cuánto aprendí de su modo de hacer teología. Ahora me quiero concentrar en tres cosas para comprender cómo caminar con Ignacio Ellacuría, y para llevarlo a la práctica.

\section{1. "Ellacuría se convirtió"}

Voy a distinguir tres momentos de ese proceso que no fue lineal.

Digamos que el proceso de conversión de Ellacuría en una primera época fue un cambio importante en su temperamento. A él mismo le oí contar, una vez pasado ese primer momento, que de estudiante jesuita tuvo discusiones fuertes con sus superiores y con el rector del teologado de Innsbruck a comienzos de los sesenta. Cuando ya en Madrid estuvo con Zubiri preparando el doctorado en filosofía, al ver los revuelos que causaba Ellacuría entre los estudiantes de la universidad de Comillas, un jesuita en autoridad le preguntó: “¿No ha pensado usted en dejar la Compañía?" Ellacuría le contestó: “Yo no. ¿Y usted?". Podía ser adusto sin contemplaciones. $Y$ a veces, podía ser tan firme en sus convicciones y decisiones que se mostraba duro y prepotente.

Por otra parte, Ellacuría también podía ser buen amigo y aun cariñoso. Era dado a defender a los jesuitas cuando eran atacados por poderosos de derecha o cuando eran incomprendidos dentro de la Compañía por defender causas justas, lo que generaba alborotos al interior de las comunidades. Por otra parte, pienso que evitó ser injusto con nadie, y que no deseaba mal a nadie. Con los años, aunque no puedo poner fechas, en buena medida se fueron limando los excesos y las aristas, sobre todo su dureza y prepotencia.

Al hablar ahora de conversión me refiero al cambio que se fue operando en él en la época en que vivió y trabajó en El Salvador entre finales de los sesenta y finales de los ochenta. Para ser más preciso diría que cambió en dos momentos que configuraron otras dos épocas, siendo la segunda de mayor profundidad personal. $Y$ quiero insistir en que no fue solo un cambio de temperamento.

En la primera época, de 1968 a 1977, Ellacuría como ser humano, jesuita y cristiano, hizo una opción por los pobres, una opción radical 
por la justicia, y llevó a cabo una lucha contra la injusticia que empobrecía a las mayorías. Sobre lo que ocurría en El Salvador, defendió la validez de la huelga de maestros de 1971 sobre la que la UCA publicó un libro poco después. Denunció el fraude electoral de 1972, sobre lo que, junto con otros, publicó el libro El año político. En 1976 defendió las promesas de reforma agraria, por pequeñas y aun falaces que fueran, de parte del gobierno del presidente Molina. Y cuando éste se echó para atrás, Ellacuría escribió su conocido editorial, "A sus órdenes mi capital". En todo ello estaba muy presente el Ellacuría pensador, filósofo y teólogo.

A nivel de su vida interior, son muestra de conversión en aquellos años los ejercicios de san Ignacio que impartió en 1969, abiertos a todos los jesuitas de la provincia, y los de 1971 a los jesuitas jóvenes recién llegados de sus estudios.

En 1977, con el asesinato de Rutilio Grande, Ellacuria entró en una segunda época en la que el cambio llegó a ser muy radical. Personalmente desde ese momento me gusta usar el término conversión al hablar de Ellacuría, como lo hice al hablar de Monseñor Romero. Esto comencé a notarlo en que hablaba de Dios de una manera diferente, y que desde el Dios que avizoró con Monseñor Romero, profundizó y radicalizó su opción por el pueblo y por la justicia, y su disposición a que le diesen muerte en el empeño.

Las muestras visibles de esa conversión son abundantes. Las resumo en tres cosas que tienen que ver con su visión radicalmente nueva de Monseñor Romero: 1 . La carta que le escribió el 9 de abril de 1977. 2. El reconocimiento público de que Monseñor era superior a la UCA, y obviamente a su persona: "él era la voz, nosotros el eco", dijo en 1985. 3. La veneración que tuvo por Monseñor Romero hasta el final.

Con esto quiero decir que no basta, como suele ser normal, tener a Ellacuría, aun con limitaciones y defectos, como una gran persona, muy capaz, ciertamente con gran inteligencia, tenaz y audaz, excepcional. Pensar así no es desatino, pero puede ser empobrecedor en algún grado si no se tiene en cuenta que Ellacuría, viviendo la realidad de El Salvador, con pobres, víctimas y mártires, y con Monseñor Romero, se convirtió.

\section{2. "Ellacuría puso a Monseñor Romero en estrecha relación con Dios"}

Ellacuría escribió una vez: "difícil hablar de Monseñor Romero, sin verse forzado a hablar del pueblo". Y así lo hizo. Siguiendo la lógica de esa 
formulación, afirmamos ahora que para Ellacuría fue "difícil hablar de Monseñor Romero sin verse forzado a hablar de Dios".

He encontrado tres textos en los que Ellacuría relaciona a Monseñor Romero explícitamente con la realidad de Dios. Cuando los leí, me llamó la atención que Ellacuría menciona simplemente a Dios de forma distinta a como lo hacía normalmente. Para expresarlo de alguna manera habló de Dios a secas, como si no quisiera tergiversar - disminuir de alguna forma su realidad hablando del Dios bíblico, ni siquiera del Dios de Jesús -aunque hay que añadir que en las palabras finales de su último escrito mencionó "el Dios salvador, el Dios liberador".

El primer texto es de los inicios del ministerio arzobispal de Monseñor Romero. Está en la carta de Ellacuría a Monseñor el 9 de abril de 1977. El segundo está en un artículo que le pidió la revista Razón y Fe pocos meses después de su asesinato. El tercero, y más radical, son las palabras que pronunció en la homilía de la misa del funeral de Monseñor en la UCA.

En estos textos, Ellacuría relaciona a Monseñor Romero con Dios a secas, pero justifica ampliamente lo que dice mencionando una serie de realidades llevadas a cabo por Monseñor cada una de las cuales es expresión de lo cristiano, expresión esta que le gustaba usar a
Ellacuría. A veces abrevio y a veces me alargo para llegar más al fondo del ser humano y cristiano Ignacio Ellacuría. A continuación recojo en lo sustancial lo que dije ante un grupo de estudiosos del pensamiento de Ellacuría cuando se reunieron en San Salvador el 12 de agosto de 2013, y lo que escribí en mi libro Conversaciones con Jon Sobrino, PPC, Madrid 2018. Veamos los tres textos.

\section{a) "He visto en la acción de usted el dedo de Dios"}

"Desde este lejano exilio quiero mostrarle mi admiración y respeto"; así comienza la carta que escribió a monseñor Romero el 9 de abril de 1977, desde su exilio en Madrid. Y menciona tres aspectos que ha captado en la actuación de Monseñor, en los que aparece lo cristiano.

"El primer aspecto que me ha impresionado es el de su espíritu evangélico... Esto me hace ver un segundo aspecto: el de un claro discernimiento cristiano... El tercer aspecto lo veo como una conclusión de los anteriores y como su comprobación. En esta ocasión y apoyado en el martirio del padre Grande, usted ha hecho Iglesia y ha hecho unidad en la Iglesia. Bien sabe usted lo difícil que es hacer esas dos cosas hoy en San Salvador. Pero la misa en la catedral y la participación casi total y unánime de todo el presbiterio, de los religiosos y de tanto pueblo de Dios muestran que en esa ocasión se ha logrado. No 
ha podido entrar usted con mejor pie a hacer Iglesia y a hacer unidad en la Iglesia dentro de la arquidiócesis. No se le escapará que esto era difícil. Y usted lo ha logrado. Y lo ha logrado no por los caminos del halago o del disimulo, sino por el camino del Evangelio: siendo fiel a él y siendo valiente con él. Pienso que mientras usted siga en esta línea y tenga como primer criterio el espíritu de Cristo martirialmente vivido, lo mejor de la Iglesia en San Salvador estará con usted y se le separarán quienes se le tienen que separar. En la hora de la prueba se puede ver quiénes son fieles hijos de la Iglesia, continuadora de la vida y de la misión de Jesús, y quiénes son los que se quieren servir de ella. Me parece que en esto tenemos un ejemplo en la vida última del padre Grande, alejada de los extremismos de la izquierda, pero mucho más alejada de la opresión y de los halagos de la riqueza injusta, que dice san Lucas".

A Ellacuría esto le llevó a decir que en Monseñor ha visto "el dedo de Dios". Desconozco por qué usó estas últimas palabras, pudiendo usar otras. Lo que me impacta es que Monseñor Romero hizo que Ellacuría "se viese movido y aún forzado a hablar de Dios".

\section{b) "Monseñor Romero fue un enviado de Dios para salvar a su pueblo"}

Los textos que siguen a continuación insisten en tres cosas. Una es el martirio de monseñor Romero. La segunda es que monseñor Romero fue y trajo salvación. La tercera es que monseñor Romero ha sido gracia para el pueblo.

Ellacuría se detiene en describir el martirio de monseñor Romero."Un 24 de marzo, caía ante el altar monseñor Romero. Bastó con un tiro al corazón para acabar con su vida mortal. Estaba amenazado hacía meses y nunca buscó la menor protección. Él mismo manejaba su carro y vivía en un indefenso apartamento adosado a la iglesia donde fue asesinado. Lo mataron los mismos que matan al pueblo, los mismos que en este año de su martirio llevan exterminadas cerca de diez mil personas, la mayor parte de ellas jóvenes, campesinos, obreros y estudiantes, pero también ancianos, mujeres y niños que son sacados de sus ranchos y aparecen poco después torturados, destrozados, muchas veces irreconocibles. No importa determinar quién fue el que disparó. Fue el mal, fue el pecado, fue el anticristo, pero un mal, un pecado y un anticristo históricos, que se han encarnado en unas estructuras injustas y en unos hombres que han elegido el papel de Caín. Solo tuvo tres años de vida pública como arzobispo de San Salvador. Fueron suficientes para sembrar la palabra de Dios, para hacer presente en su pueblo la figura de Jesús; fueron demasiados para los que no pueden tolerar la luz de la verdad y el fuego del amor". 
Estas palabras no necesitan comentario. Son Ellacuría puro. Comienza con la pasión, pero a continuación se sigue preguntando qué había hecho en su vida monseñor Romero. $Y$ en formulación concentrada -muy querida para Ellacuría- "lo que hizo monseñor fue traer salvación a su pueblo" "No trajo salvación como un líder político, ni como un intelectual, ni como un gran orador", dice Ellacuría. Se puso a anunciar y realizar el Evangelio con plena encarnación y en toda su plenitud, puso a producir la fuerza histórica del Evangelio. Comprendió "de una vez por todas"-dice Ellacuría con fuerza y criticando la ausencia habitual de lo que dirá a continuación- "que la misión de la Iglesia es el anuncio y la realización del Reino de Dios, que pasa ineludiblemente por el anuncio de la Buena Nueva a los pobres y la liberación de los oprimidos. Monseñor buscó y trajo una salvación real del proceso histórico. Habló a favor del pueblo para que él mismo construyese críticamente un mundo nuevo, en el cual los valores predominantes fueran la justicia, el amor, la solidaridad y la libertad".

Ellacuría vio en monseñor Romero don y gracia."Fue un enviado", dice, no mero producto de nuestras manos. Se convirtió -no para todos por igual-en el gran "regalo de Dios", y un regalo muy especial."Los sabios y prudentes de este mundo, eclesiásticos, civiles y militares, los ricos y poderosos de este mundo decían que hacía polí- tica. Pero el pueblo de Dios, los que tienen hambre y sed de justicia, los limpios de corazón, los pobres con espíritu, sabían que todo eso era falso... Nunca habían sentido a Dios tan cerca, al espíritu tan aparente, al cristianismo tan verdadero, tan lleno de gracia y de verdad". "Todo ello le ganó el amor del pueblo oprimido y el odio del opresor. Le ganó la persecución, la misma persecución que sufría su pueblo. Así murió y por eso lo mataron".

En lo personal, pocas palabras de Ellacuría o de Rutilio o de Monseñor me han impactado más que estas. En Monseñor Romero "nunca habían sentido a Dios tan cerca”. A Ellacuría esto le llevó a decir que Monseñor Romero fue "un enviado de Dios".

\section{c) "Con monseñor Romero, Dios pasó por El Salvador"}

El pensamiento de Ellacuría sobre Monseñor alcanzó su punto culminante en sus conocidas palabras "Con monseñor Romero, Dios pasó por El Salvador". Las pronunció en la homilía en el funeral que tuvimos en la UCA. Ellacuría se expresa con máxima radicalidad lingüística y conceptual: con monseñor Romero Dios se hizo presente en la historia salvadoreña -como con Jesús de Nazaret Dios pasó por Galilea y Judea. En estas palabras hay genialidad de pensamiento, y no conozco pastores ni teólogos, ni filósofos ni políticos, que conceptualicen y formulen reali- 
dades con tal radicalidad. Las palabras pueden extrañar y sorprender a creyentes, y el impacto de monseñor Romero en Ignacio Ellacuría también a no creyentes. Pudieran parecer poco científicas y poco universitarias, y, aunque teologales, quizás no suenen en exceso religiosas y piadosas, alejadas del lenguaje de Calcedonia. Pero debo confesar que para mí son verdaderas y son fructíferas. Al menos expresan más verdad y producen más frutos que otras que he escuchado sobre monseñor Romero.

Ellacuría vio en la historia de Monseñor una ultimidad y una radicalidad que, en ese grado, no encontró en ninguna otra realidad, aunque esas realidades fuesen la verdad y la libertad, la democracia y el socialismo, ni, que yo recuerde, en otras personas del pasado, por muy venerables que hubiesen sido. Vio que el paso de Dios en Monseñor producía bienes, personales y, novedosamente, bienes sociales difíciles de conseguir, y una vez conseguidos, difíciles de mantener. Producía justicia sin ceder ante la injusticia. Producía defensa y liberación de los oprimidos, y producía compasión y ternura hacia los indefensos. Producía verdad sin componendas, no aprisionada por la mentira, ni por el eterno peligro de ceder a lo políticamente correcto. $Y$ mantenía una esperanza que no muere...

A Ellacuría, monseñor Romero le habló, de un Dios de pobres y mártires, ciertamente, liberador, exigente, profético y utópico. En un palabra, le habló de lo que en Dios hay de "más acá". Pero también le habló de lo que en Dios hay de inefable, no adecuadamente historizable, de lo que en Dios hay de "más allá", de misterio insondable y bienaventurado.

Y a quien el término "Dios" le resulte extraño, piense en otras palabras de Ellacuría: "Lo último de la realidad es el bien y no el mal". Eso es lo que con monseñor Romero pasó por El Salvador.

\subsection{Ellacuría fue llevado por la fe de Monseñor Romero}

Quiso caminar- pienso que sin decírselo a sí mismo explícitamentecon y como Monseñor Romero. Y aunque de estas cosas solo se puede hablar con temor y temblor y solo se puede entrar en ellas de puntillas, pienso que su ilusión fue creer como Monseñor Romero. El no era dado a hablar de estas cosas, pero eso es lo que capté y se me impuso, sobre todo después del asesinato de Monseñor.

No fue siempre así. Hasta 1977, fueron años de desencuentro entre ambos. Baste una muestra. Por encargo de la Conferencia Episcopal 
de El Salvador, en 1974, Monseñor Romero escribió una recensión del Libro de Ellacuría Teología Política. La recensión fue crítica. Estaba basada en argumentos teológicos de los años cuarenta, con lógica, pero sin el espíritu de Medellín. En cualquier caso sí estaba escrita con respeto y educación, lo cual no ocurría siempre cuando hablaban los obispos.

Ellacuría a su vez fue crítico de Monseñor, pues, aunque este aceptase teóricamente a Medellín por ser un documento de la jerarquía eclesiástica, no parecía que se sintiese cómodo con Medellín y menos con las teologías latinoamericanas que lo pusieron a producir. Esto llevó a Romero a mostrar fuerte desconfianza y a expresar fuertes críticas contra el clero, seminaristas, comunidades, también contra la UCA, que buscaban ponerlo en práctica.

Con el asesinato de Rutilio Grande el 12 de marzo de 1977 ocurrió con claridad el cambio y la conversión de Monseñor Romero. Y yo empecé a percibir también un inicio de conversión en Ignacio Ellacuría. El encuentro entre Romero y Ellacuría se hizo, desde entonces, cada vez más coincidente en la visión histórica de la sociedad salvadoreña, en lo que debía ser el seguimiento de Jesús y la praxis de la Iglesia. Y a la base estaba la comprensión de Dios como Dios de vida en lucha con los ídolos de muerte. En lo personal, pienso que la relación entre ambos llegó a ser muy cercana. En el caso de Ellacuría, a quien conocí más de cerca, su relación con Monseñor fue entrañable. Ellacuría llegó a tener veneración por Monseñor Romero.

Por decirlo en otras palabras creo que Ignacio Ellacuría deseaba ser discípulo de Monseñor. Cuando tenía 47 años y llevaba trabajando 10 en la UCA a Ellacuría se le "apareció" -opthe; Monseñor Romero. Y uso el término "aparecer", lenguaje en que se narran las apariciones del resucitado, conscientemente, para expresar, con todas las analogías del caso, lo que en ello hubo de inesperado, no sé cuánto de destanteador, y ciertamente muy mucho de bienaventurado.

No fue el primer encuentro que tuvo Ellacuría con personas a quienes consideró maestros, mentores o padres en el espíritu: Miguel Elizondo en el noviciado, Aurelio Espinosa Polit en el estudio de las humanidades en Quito, el poeta vasconicaragüense Martínez Baigorri. Por lo que toca a la teología durante cuatro años fue alumno de Rahner en Innsbruck. Y por lo que toca a la filosofía estudió y trabajó con Zubiri, fue su colaborador intelectual más cercano, y de varias formas inspirador suyo hasta su muerte.

Ellacuría les estuvo agradecido, y les podía reconocer -lo que decía con claridad en el caso de Zubiri- superioridad en el quehacer intelectual. 
Pero, de algún modo, también podía considerarse "colega" de quienes habían sido sus mentores. Sin embargo, nunca se consideró colega de Monseñor Romero. Para Ellacuría, Monseñor fue un referente que iba delante. Solía decir: "Monseñor ya se nos había adelantado".

En 1985, reconoció pública, explícita y solemnemente, la superioridad de Monseñor Romero sobre la UCA.
El 22 de marzo, a los cinco años de su martirio la UCA concedió a Monseñor un doctorado póstumo honoris causa en teología. En esta ocasión, Ellacuría tuvo un importante discurso sobre Monseñor. Quiso contestar a las acusaciones de que la UCA manipulaba a Monseñor Romero, y sobre todo quiso confesar públicamente la importancia de Monseñor para la UCA y la superioridad de Monseñor sobre la UCA.

\begin{abstract}
"Se ha dicho malintencionadamente que Monseñor Romero fue manipulado por nuestra universidad. Es hora de decir pública y solemnemente que no fue asi. Ciertamente monseñor Romero pidió nuestra colaboración en múltiples ocasiones y esto representa y representará para nosotros un gran honor, por quien nos la pidió y por la causa para la que nos la pidió [...], pero en todas esas colaboraciones no hay duda de quién era el maestro $y$ de quién era el auxiliar, de quién era el pastor que marca las directrices y de quién era el ejecutor, de quién era el profeta que desentrañaba el misterio y de quién era el seguidor, de quién era el animador y de quién era el animado, de quién era la voz $y$ de quién era el eco".
\end{abstract}

Ellacuría confesaba humildemente -a lo que no era dado-y agradecidamente -a lo que sí era dadola deuda de la UCA con Monseñor. $Y$ es importante recordar qué fue lo más específico de ese impacto. Ciertamente le impactó, como a muchos otros, su profecía y denuncia, su compasión y esperanza, su cercanía a los pobres y su lucha por la justicia, su disponibilidad a que le arrebatasen la vida, y el mantenerse fiel hasta el final sin dejarse desviar por ningún riesgo ni amenaza. Por lo que toca a esto último, en contra de lo que decían algunos amigos de Monseñor, Ellacuría aprobaba los riesgos que este asumía, e insistía. "Monseñor debe aceptar correr esos riesgos. Es lo que debe hacer".

Pero pienso que el impacto más novedoso, y el más poderoso, se lo produjo la fe de Monseñor Romero. La fe de Monseñor Romero suponía para Ellacuría alguna forma de discontinuidad mayor. Pienso que Ellacuría sintió que en Monseñor 
Romero había algo diferente, superior, no sólo cuantitativa sino cualitativamente. A él, no le empequeñecía, pero le ayudaba a saberse y ubicarse mejor como ser humano.

Lo que acabamos de decir lo podemos reformular, con sencillez y algo de audacia, diciendo que Ellacuría fue "discípulo de Monseñor Romero en la fe". Dando un paso más, un paso más, "Ellacuría fue llevado en la fe y por la fe de Monseñor".

Lo he dicho muchas veces. En 1969 en una reunión en Madrid le oí decir: "Rahner lleva con elegancia sus dudas de fe", con lo cual venía a decir -esa fue mi convicción-que tampoco para él la fe era algo obvio. Sus palabras no me sorprendieron, pues aquellos eran años recios para la fe, la mía propia y la de otros compañeros e incluso profesores.

Como muchos otros en aquellos años, pienso que Ellacuría anduvo a vueltas con Dios. En palabras de la Escritura, pienso que luchó con Dios, como Jacob. Lo que creo que ocurrió años después es que Monseñor Romero, sin proponérselo Ellacuría, le impulsó y le capacitó para ponerse activamente, y mantenerse, ante el misterio último de la realidad.
De Monseñor le impresionó profundamente cómo se remitía a Dios, no solo en la reflexión y en la predicación, sino en la más profunda realidad de su vida. Dios era para Monseñor absolutamente real. Y Ellacuría vio que con ese Dios Monseñor humanizaba a personas y traía salvación a la historia. La fe de monseñor Romero se le impuso a Ignacio Ellacuría como algo bueno y humanizante. Se alegraba de que Monseñor fuese hombre de fe, y de que esa fe fuese contagiosa. Algo o mucho -en definitiva, sólo Dios lo sabe- pienso que se le pegó a Ellacuría. El misterio cobró novedad y cercanía.

Y ese Ellacuría mencionaba a "Dios" con toda naturalidad para dar fuerza a una idea, también cuando no tenía por qué hacerlo. En una dura crítica escribió: "todo importa más que escuchar realmente la voz de Dios que [...] se escucha en los sufrimientos como en las luchas de liberación del pueblo". Y más allá de temas concretos, remitiéndose al pensar y sentir de Monseñor Romero Ellacuría hablaba con toda naturalidad de la trascendencia. Citamos un texto, significativo porque incluye muchos temas importantes, que culmina con la trascendencia de Dios.

\footnotetext{
"Monseñor Romero nunca se cansó de repetir que los procesos políticos, por muy puros e idealistas que sean, no bastan para traer a los hombres la liberación integral. Entendía perfectamente aquel dicho de san Agustín que para ser hombre hay que ser "más" que hombre. Para él, la historia que solo fuese
} 
humana, que solo pretendiera ser humana, pronto dejaria de serlo. Ni el hombre ni la historia se bastan a sí mismos. Por eso no dejaba de llamar a la trascendencia. En casi todas sus homilias salía este tema: la palabra de Dios. La acción de Dios rompiendo los límites de lo humano".

Monseñor Romero vino a ser para Ellacuría como el rostro del misterio que asoma en nuestro mundo. Con exquisita delicadeza Monseñor le ofrecía aquello en lo que él era eximio y en lo que los demás somos mucho más limitados.

Un día en 1983, al regreso de su segundo exilio, estando refugiada la comunidad en Santa Tecla, Ellacuría presidió la eucaristía y nos habló del "Padre celestial". No era lenguaje muy suyo, pero algo importante y bueno quería decir con estas palabras el Ellacuría cerebral y crítico. Pero también pasó por oscuridad. Nunca sentí que caía en desesperación, pues siempre se le ocurría cómo seguir trabajando, pero sí sentía en él un malestar personal. Las cosas no marchaban nada bien para el país, y Ellacuría no parecía sentir un asidero seguro para su lucha por el diálogo. Una vez me dijo, como de pasada, "solo queda la estética".

Como Monseñor, tomó en serio la posibilidad de una muerte violenta. No hablaba de eso, y ciertamente no para darse importancia. Pero era muy consciente de esa posibilidad. Conmigo habló alguna vez. Meses antes de su muerte me dijo; "ahora que trabajo por el diálogo y la nego- ciación mi vida corre más peligro que cuando me tenían por izquierdista y revolucionario". Y, cual estoico ilustrado, me dijo también: "Me han dicho que el dolor de un disparo solo dura veinte segundos". En medio de estas experiencias personales sobre el sentido y sinsentido de la vida, Ellacuría siguió luchando.

El talante de constatar y desenmascarar la negatividad de la realidad le acompañó hasta el final de su vida. En su último discurso el 6 de noviembre de 1989, al recoger en Barcelona el premio Comín, dijo: "nuestra civilización está gravemente enferma y [...] para evitar un desenlace fatídico y fatal, es necesario intentar cambiarla desde dentro de sí misma". De ahí, la imperiosa necesidad de revertir la historia. Sin embargo, Ellacuría insistió también hasta el final en que en la negatividad puede haber principio de salvación. Escribió repetidas veces sobre la salvación que trae el siervo de Jahvé, sufriente y destrozado; los mártires asesinados, una iglesia de pobres y oprimidos. Y en el discurso de Barcelona para sanar a la sociedad enferma se remitió a lo que está abajo en la historia. "Sólo utópica y esperanzadamente uno puede creer y tener ánimos para 
intentar con todos los pobres y oprimidos del mundo revertir la historia, subvertirla y lanzarla en otra dirección".

\section{Ignacio Ellacuría Beascoetxea, una antorcha}

En el afiche de aniversario de este año se dice de los mártires de la UCA que "llenan de luz la historia". Y está muy bien dicho. Yo prefiero hablar de ellos como antorcha antes que como luz. Una cosa es destapar la verdad enterrada vilmente con la mentira, y otra desentrampar la verdad, entrampada por multitud de intereses que están dispuestos a todo para que la verdad no salga a la luz. Siguiendo con metáforas, para lo primero es necesario, y puede bastar, ser una especie de lámpara que ilumina. Para lo segundo es necesario ser antorcha que ilumine y que arda para mover el corazón y eliminar lo que impide ve ver.

Una antorcha surge con alguna persona de extremada lucidez en su juicio sobre cómo es y cómo está objetivamente la realidad, cómo hay que encargarse de ella, cómo hay que cargar con ella y cómo hay que dejarse cargar con ella. Ente nosotros, antorcha fue el Padre Rutilio Grande y Monseñor Romero. Antorcha fue Ignacio Ellacuría. Y, aunque de diversa forma, antorcha fue Rufina Amaya.

En sus últimos años escuché a Ellacuría tres frases que lo mostraban con la lucidez y el vigor de una antorcha. Las recuero muy brevemente.

"La necesidad de una tercera fuerza" Lo mencionó en una cátedra de realidad nacional. No gustó a la derecha, lo cual no era sorpresa, pero tampoco a varios de la izquierda, pues Ellacuría habría caído en tercerismo, en un tercer sistema entre socialismo y capitalismo. La tercera fuera era una fuerza social en la que todos -al menos un grupo numeroso-estuvieran totalmente de acuerdo en una cosa: ni un muerto más. Lo que Ellacuría buscaba es acumular voluntades que quisieran que terminase la guerra y la muerte en el país, aunque cada uno pudiese mantener sus propias ideas y utopías. En lo personal me pareció una idea genial, cosa típica de Ellacuría, y que mantuvo a pesar de las críticas. Y me recordaba a Monseñor Romero que veía lo peor de lo que estaba sucediendo en el país en que los campesinos salvadoreños se matasen unos a otros.

"Hay que empujar el carro de la historia" Varias veces pronunció esta metáfora para responder a la pregunta de lo que hay que hacer. Tal como lo entendí, Ellacuría exigía una actitud humana -y cristiana- de 
lo que debía estar transida cualquier actividad para cambiar y revertir la historia.

Para explicar mejor en qué consiste el carro de la historia, suelo parodiarlo de esta manera. El carro puede ser un carro normal, un carromato, casi nunca un Cadillac. Puede rodar por buenas autopistas, rara vez, o por caminos pedregosos o embarrados. Pero lo que hay que empujar es siempre el carro de la historia real, tal como la vivimos. $Y$ a esa realidad no solo hay que conocer y juzgar, sino empujar. Y hay que empujar de atrás para adelante, con nuestras fuerzas sea cual fuere el agotamiento propio. Lo que no podemos dejar de hacer es empujar.

"Salva la civilización de la pobreza". Ellacuría estaba convencido que un mundo configurado por la civilización de la riqueza, que se construye acumulando y en que se disfruta gozando de lo acumulado, solo podrá ser salvado por una civilización de la pobreza. Creo que ya he dicho que desde 1980 a 1989, Ellacuría abordó el tema en cinco ocasiones. Admiradores de Ignacio Ellacuría, entre ellos Pedro Casaldáliga y González Faus, prefieren no usar el lenguaje de "civilización de la pobreza", sino otro lenguaje en la línea de "civilización de la austeridad compartida”. Sin embargo, Ellacuría nunca cambió el término pobreza, para proclamar una civilización que salve y sane a una sociedad enferma de muerte.

A esas actitudes, con esa clarividencia y precisión, las he llamado antorcha.

Termino. Ellacuría dijo una vez: "En tiempos como estos, no hay cosa más práctica que la teología”.

¿Y Dios? El último artículo que publicó en la Revista Latinoamericana de Teología en agosto de 1989 trataba de utopía y profetismo. Ellacuría terminó con estas palabras:

"Estos hombres nuevos siguen anunciando firmemente, aunque a oscuras, un futuro siempre mayor, porque más allá de los sucesivos futuros históricos se avizora el Dios salvador, el Dios liberador".

En estas palabras, percibo el aliento de Monseñor Romero. 